\title{
The Pittsburgh Diabetes Mellitus Study
}

\section{3: An Increased Prevalence With Older Maternal Age}

\author{
Diane K. Wagener ${ }^{1,}$, , R.E. LaPorte', T.J.Orchard ${ }^{1}$, D.Cavender ${ }^{1}$, L.H. Kuller ${ }^{1}$ and A. L. Drash ${ }^{3}$ \\ Departments of ${ }^{1}$ Epidemiology, ${ }^{2}$ Psychiatry and ${ }^{3}$ Pediatrics, University of Pittsburgh, Pittsburgh, USA
}

\begin{abstract}
Summary. A series of patients having onset of Type I (insulindependent) diabetes mellitus before age 17 years was identified from consecutive admissions to the Children's Hospital of Pittsburgh. Family history data were obtained yielding 1006 families ( 1085 cases) with complete information. The prevalence of diabetes among the children differed by birth order, with a greater number than expected among first born. There was also an increased prevalence among children born to mothers older than 35 years, as well as an increased prevalence among children of very young mothers. The increased prevalence of diabetes among offspring of older mothers was
\end{abstract}

apparent even after life table age corrections were made. However, both the increased prevalence among first born children and the increased prevalence among children of very young mothers could be attributed to an older attained age of these children in this particular population. This indicated that the maternal age effect was present but a birth order effect was absent when age was taken into account.

Key words: Type I diabetes mellitus (juvenile), birth order, maternal age.

\section{Introduction}

Few studies have looked at the effects of maternal age or birth order on the risk of Type I (insulin-dependent) diabetes mellitus. In one recent report on a series of 624 diabetic children [1], maternal age was positively correlated with increased risk of Type I diabetes. It was reported that advanced maternal age, rather than multiparity, was the primary risk factor. In a previous publication we analyzed the birth order of diabetic subjects and concluded that when comparisons were made between families of the same size, diabetic cases tended to have a higher birth order [2]. We did not examine whether maternal age was related to the risk of developing Type I diabetes. If there was a maternal age effect, the tendency for the diabetic subjects to have been higher in the birth order might have been an artefact, since higher birth order children would be more likely to have older mothers.

We therefore investigated the relationship between maternal age, birth order and risk of developing Type I diabetes in the same population of families from our registry of cases from Children's Hospital of Pittsburgh.

\section{Subjects and Methods}

\section{Subjects}

The collection and details of the families who were included in this analysis have been described elsewhere [2,3]. The cases were individuals admitted to the Children's Hospital of Pittsburgh who were diagnosed during 1965-1981, were under age 17 years at diagnosis, and were discharged on insulin. The total number of admissions fulfilling these criteria was 1280 . In a very few cases we found that the child was either no longer taking insulin or that the diabetes was secondary to another disorder, such as cystic fibrosis or Downs' syndrome. These cases ( $<1 \%$ of total) were omitted. Below we refer to the remaining population as our Children's Hospital (CHP) registry. As indicated in previous reports, the CHP registry is likely to be representative of the total population because over $70 \%$ of the Allegheny County cases with onset under age 17 years were seen at the Children's Hospital. Continued comparisons between our hospital-based CHP registry and our population-based Allegheny County registry have resulted in virtually identical results.

Family histories were obtained by mailed questionnaires and telephone interviews from over $95 \%$ of cases. After exclusion of the 35 adopted patients and their families, there remained 1143 families, each consisting of index case and first-degree relatives. In 137 of the families we had incomplete information regarding paternity or ages of family members. Therefore, the following analysis was carried out on 1006 families. 
Table 1. Prevalence of Type I diabetes among children by maternal age and by birth order

\begin{tabular}{lclll}
\hline & $\begin{array}{l}\text { Numbers } \\
\text { of children } \\
\text { (total } \\
n=3282)\end{array}$ & Prevalence & $\begin{array}{l}\text { Current } \\
\text { age } \\
\text { (years) }\end{array}$ & $\begin{array}{l}\text { Average age } \\
\text { of onset } \\
\text { (years) }\end{array}$ \\
\hline Birth order & & & & \\
1 & 1006 & 39.7 & 19.1 & 8.4 \\
2 & 929 & 29.6 & 16.9 & 9.1 \\
3 & 655 & 31.1 & 15.9 & 8.8 \\
$4+$ & 692 & 29.5 & 14.7 & 8.5 \\
\multicolumn{1}{l}{ Maternal age (years) } & & & \\
Under 21 & 335 & 39.4 & 19.1 & 8.8 \\
$21-25$ & 1132 & 31.9 & 18.2 & 8.9 \\
$26-30$ & 939 & 28.6 & 16.5 & 8.7 \\
$31-35$ & 571 & 32.9 & 15.3 & 8.9 \\
Over 35 & 285 & 45.3 & 13.3 & 7.6 \\
\hline
\end{tabular}

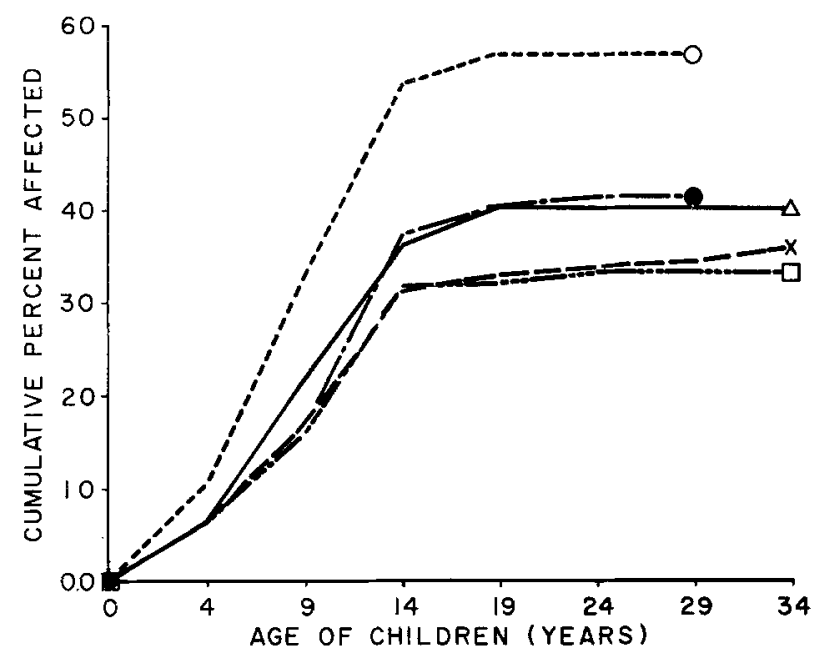

Fig. 1. The cumulative frequency of Type I diabetes in children, grouped according to the age of the mother at the birth of the child. $\Delta=$ maternal age less than 21 years, $x=$ maternal age $21-25$ years, $\square=$ maternal age 26-30 years, $\quad=$ maternal age $31-35$ years, $\mathrm{O}=$ maternal age 35 years or older

\section{Methods}

In the analyses described below, differences between proportions were tested using a t-test for proportions [4]. The life table analysis, or survival analysis, was performed using the actuarial approach of Cutler and Ederer [5]. The BMDP statistical package [6] was used to analyze these life tables.

Several biases in birth order data are introduced into any study where each family included is identified at the onset of a disease in one of the children. One source of bias is that when a new family is identified, the index case is usually the first case in the family. Therefore, older siblings are necessarily unaffected. Consequently, the affected index child will usually have a higher birth order than a random child in these families. Another source of bias is that some sibships may be incomplete (i. e., do not include siblings as yet unborn) [7-9]. A partial solution to the problem of incomplete sibships, proposed by Barker and Record [8], is to include only those siblings born during a finite period of time and, further, to include only those families in which the affected (diabetic) child was born during that finite period. This is known as a censored sample. Barker and Record applied this technique to congenital malformations. Since diabetes usually does not have onset at the time of birth, we selected a period of the time which corresponded to siblings who were currently aged 15-30 years. Those children who were going to develop diabetes would probably have developed it by the time of sampling, the period of greatest risk being ages $10-17$ years.

The prevalence rates and survival analyses were calculated for the entire population of siblings (see below). In addition prevalence rates were calculated for the censored sample of older siblings. Barker and Record also proposed some specialized statistics for birth order which were not amenable to significance tests [8]. Therefore, Gladstein and Spence combined the censored sample technique [9] with a birth order statistic proposed by Haldane and Smith [10]. This latter statistic has a significance test. The Haldane-Smith statistic gives weights to the various families which depend on the total numbers of children and placement of the diabetic children in these families. The weight for a family is the expectation for the probability of finding such a family. The observed sum of the birth-ranks is multiplied by six and referred to as $\mathrm{A}$. The A statistic is compared with the theoretical mean value for the data set. If the value of $\mathrm{A}$ is larger than the mean, there is an increased risk to higher birth order children and vice versa for a value of A smaller than the mean. The Haldane-Smith statistic was calculated for these data.

\section{Results}

Table 1 presents the relationship between maternal age or birth order and the risk of children developing diabetes. Of the 1006 children who were the first born in their families, $39.7 \%$ were diabetic. Overall $33 \%$ of the 3282 children (1085 cases) were diabetic. Included in Table 1 are 10 families with mothers who also had Type 1 diabetes. These families were included in the analysis since the pattern of maternal age and birth order in them was similar to that in the remainder; the prevalence rates among the 26 children born to diabetic mothers in the first four maternal age groups were 50 , 37,36 , and $67 \%$, respectively. (There were no children born to diabetic women aged $>35$ years).

As seen in Table 1, there appeared to be an increased prevalence of diabetes among offspring born to mothers aged $>35$ years $(p<0.001)$. This was also true within each birth-order class when the data were disaggregated (not shown). There was also a suggestion of increased prevalence in children born to mothers under age 21 years $(p<0.01)$. This tendency, however, may have been an artefact since the current or attained ages of the children in this maternal age class were generally greater than those of the other children (Table 1). As well as other authors, we have demonstrated that the peak age of onset of diabetes is approximately 12-14 years. Therefore, most of the children from the younger group of mothers have gone through the "major risk period' and had the 'opportunity' to develop diabetes since their mean age is 19 years, whereas many children from mothers aged $>35$ have not had such an 'opportunity' as their mean age is only 14 years. To control for the differences in ages of the cases, a life table approach was employed. In this method all siblings were entered into the analysis at birth and followed either until the development of diabetes or until the end of the study period. It was then possible to examine the 


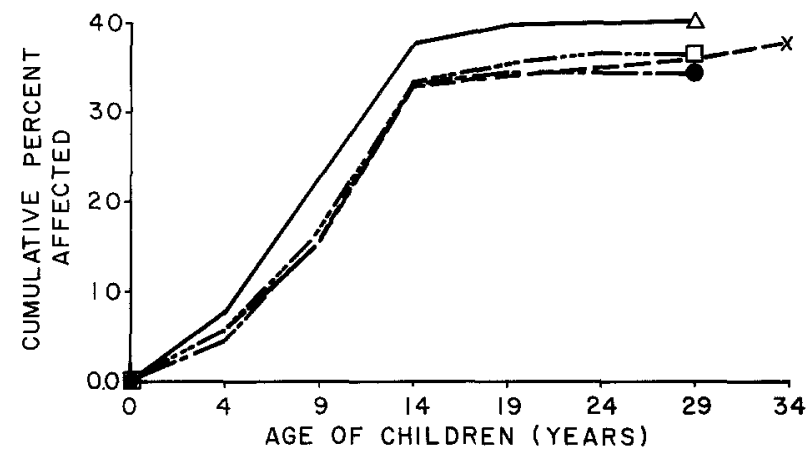

Fig. 2. The cumulative frequency of Type I diabetes in children, grouped according to the birth order of the child. $\Delta=$ first child, $x=$ second child, $\square=$ third child, $\mathbf{Q}=$ fourth or later child

Table 2. Prevalence of Type I diabetes among older children (aged $15-30$ years) by maternal age and by birth order

\begin{tabular}{lll}
\hline & $\begin{array}{l}\text { Numbers of children } \\
\text { (total } n=1362)\end{array}$ & $\begin{array}{l}\text { Prevalence } \\
(\%)\end{array}$ \\
\hline Birth order & & \\
1 & 430 & 27.4 \\
2 & 425 & 38.6 \\
3 & 280 & 37.9 \\
4 & 227 & 36.1 \\
& & \\
Maternal age (years) & & 37.9 \\
Under 21 & 145 & 31.4 \\
$21-25$ & 474 & 30.7 \\
$26-30$ & 411 & 39.3 \\
$31-35$ & 242 & 50.0 \\
Over 35 & 90 & \\
\hline
\end{tabular}

risk for developing diabetes at different ages, controlling for differences in the distribution of ages in the siblings.

The resulting life table curves are given in Figure 1. Both the Breslow statistic (55.5) and Mantel statistic (59.2) indicate that these life tables are significantly different at the 0.001 level. The results indicate that the children born to mothers after age 36 years were almost twice as likely to develop diabetes as children of younger mothers.

A similar life table analysis showed no differences in prevalence of Type 1 diabetes between the children from different birth order groups (Fig. 2). Thus, the overall increase of Type I diabetes in the first birth order in our population could be attributed to the greater age attained in this group. These results indicate that the relationship of maternal age to risk is not a consequence of the fact that children born to women at a later age are usually of later birth orders.

There was, therefore, an increased prevalence of diabetes among children born to older women, even though these children had not lived through the period of greatest risk, as indicated by their younger current age. These two observations are reconciled by noting the younger average age of onset among the children of older mothers (Table 1). This suggests that the maternal age effect was associated with an early onset of Type I diabetes, an implication confirmed in the life table analyses which showed that the slope of the curve for children born to mothers after age 36 years was much steeper. That is, the increased risk was apparent at an early age in the children and persisted.

The corrections for bias were then applied to the data and the results noted above were still apparent. Table 2 gives the prevalence by birth order and maternal age groups for the censored sample of older siblings. Note that all the children in this sample would have lived through most or all of the period of greatest risk for developing diabetes. The Haldane-Smith statistic [10] was significant for an increased risk in higher birthorder children $(A=7836$; mean \pm SEM: $6912 \pm 5.8$, $p<0.001$ ). In Table 2 it can be seen that the increased prevalence in the whole cohort of first birth-order siblings was no longer apparent. The Haldane-Smith statistic does not take into account the current ages.

When a life table analysis was performed on these data, the birth order effect disappeared. However, the maternal age effect was maintained for the older sibling population. Therefore, even when the population is chosen such that most of the children would have lived through the period of greatest risk, the maternal age effect was present, but a birth order effect was not.

One concern with our data was that we might have a bias towards older mothers in our sibling cohort. If such were the case, our maternal age effect might be an artefact of our identified population. Therefore, the agespecific birth rates were compared with the rates for the general population of Allegheny County (Allegheny County Health Department, Department of Vital Statistics). In 1970, the percentage of births to mothers in the age groups less than $20 ; 20-24 ; 25-34$; and $35+$ years were $13,35,44$, and $8 \%$ respectively. The comparable age specific birth rates for our population were calculated to have been $6,31,52$ and $11 \%$, respectively. Thus, our population of diabetic children and their siblings did not appear to be significantly biased toward the older mothers. (No comparable data for birth order were available).

\section{Discussion}

The data analysed here are not general population incidence data. That is, we are not calculating risk per se because all the families were ascertained due to the presence of at least one child with diabetes. Instead we are estimating the prevalence of diabetes with respect to birth order and maternal age within these families. The expectation is that neither birth order nor maternal age should have an effect on the prevalence.

The prevalence of diabetes among children of older mothers was increased in our population, both for the whole cohort and for the censored sample of older chil- 
dren. Among the 26 children of Type I diabetic mothers, there was also an indication of a maternal age effect. However, for the total sample, birth order showed no effect when current ages of the children were taken into account. Likewise, the greater prevalence (Table 1) for the children of very young mothers disappeared when a life table approach was used. Therefore, the greater prevalence among children of younger mothers was a result of the fact that most of these children, who were usually of birth order one, had lived through the ages of greatest risk for developing diabetes and, consequently, developed the disease.

The life table curve for children born to mothers older than 35 years differed in two respects from the other curves (Fig. 1). First, the overall cumulative incidence to the children was greater. Secondly, the rate of increase in cumulative incidence was much more rapid among children of older mothers than in the other groups. This increased incidence of early onset is reflected in the younger average age of onset of these children born to older mothers (Table 1).

The effects of maternal age and birth order have been studied for a variety of congenital malformations [11-17]. There is general agreement that there is a positive association between increased maternal age and the risk of Down's syndrome [11]. However, there appears to be a slight negative association between birth order and Down's syndrome [12-14]. The effects of maternal age on the risks of central nervous system malformations, cleft lip and palate and congenital heart defects are not as consistent, but in general show positive or Ushaped maternal age effects [14-17]. Any associations of birth order with these various abnormalities are either negative or non-existent. The increase in risk for congenital malformations in children born to older women may be due to accumulating changes in gametes, possible increased permeability of the placenta to teratogens, or age effects [14].

The mechanism for the increased prevalence and younger age at onset of Type I diabetes cannot be resolved by this study. However, one speculation is that the intrauterine environment may have an effect. An example of how experience in utero can affect the risk of developing diabetes in the offspring is the congenital rubella syndrome. Children exposed in utero to rubella have a markedly increased risk of developing diabetes [18]. Only about $20 \%$ of these children, however, developed the insulin-dependent type.

Acknowledgements. We wish to thank the staff of the Pittsburgh Diabetes Mellitus Study for their many intensive hours of work on the collection of these data.

This study was conducted at Children's Hospital of Pittsburgh, University of Pittsburgh and supported by grants from The National Institutes of Health AM 24021. Drs. Wagener and Orchard were sup- ported by The National Institute of Mental Health MH 00299 and National Institutes of Health AM 00885, respectively.

\section{References}

1. Flood TM, Brink SJ, Gleason RE (1982) Increased incidence of Type I diabetes in children of older mothers. Diabetes Care 5: 571-573

2. Wagener DK, Kuller L, Orchard T, LaPorte R, Rabin BS, Drash A (1982) Pittsburgh diabetes mellitus study. II. Secondary attack rates in siblings. Am J Epidemiol 115: 868-878

3. Wagener DK, Sacks JM, LaPorte RE, MacGregor JM (1982) The Pittsburgh Study of insulin-dependent diabetes mellitus. I. Risk for diabetes among relatives of IDDM. Diabetes 31: 136-114

4. Sokal RR, Rohlf FJ (1969) Biometry: The principles and practice of statistics in biological research. Freeman, San Francisco, pp 607-609

5. Cutler SJ, Ederer F (1958) Maximum utilization of the life table method in analyzing survival. $\mathrm{J}$ Chron Dis $8: 669-712$

6. Dixon WJ, Brown MB (1979) BMDP-79: Biomedical Computer Programs P-Series. University of California Press, Los Angeles, pp 743-770

7. Greenwood M, Yule U (1914) On the determination of size of family and of the distribution of characters in order of birth from samples taken through members of sibships. J R Stat Soc 77: 179-197

8. Barker DJP, Record RG (1967) The relationship of the presence of disease to birth order and maternal age. Am J Hum Genet 19: 433-449

9. Gladstein K, Spence MA (1978) A statistical analysis of birth-order effects with application to data on pyloric stenosis. Am J Hum Genet 42: 213-217

10. Haldane JBS, Smith CAB (1948) A simple exact test for birth-order effect. Am Eugen Lond 14: 117-124

11. Summitt RL (1979) Cytogenetic diseases. In: Jackson LG, Schimke RN (eds) Clinical genetics: a source book for physicians. Wiley and Sons, New York, pp 35-84

12. Smith A, Record RG (1955) Maternal age and birth rank in the aetiology of monogolism. Br J Prev Soc Med 9: 51-55

13. Stark CR, Mantel N (1966) Effects of maternal age and birth order on the risk of monogolism and leukemia. J Natl Cancer Inst 37: 687-698

14. Hay S, Barbano H (1972) Independent effects of maternal age and birth order on the incidence of selected congenital malformations. Teratology 6:271-280

15. MacMahon B (1952) Association of congenital malformations of the heart with birth rank and maternal age. $\mathrm{Br} \mathrm{J}$ Soc Med 6: $178-182$

16. Record RG, McKeown T (1949) Congenital malformations of the central nervous system. I. A survey of 930 cases. Br J Soc Med 3: 183-219

17. Edwards JH (1958) Congenital malformations of the central nervous system in Scotland. Br J Prev Soc Med 12: 115-130

18. Menser MA, Forrest JM, Bransby RD (1978) Rubella infection and diabetes mellitus. Lancet I: $57-60$

Received: 25 November 1982

and in revised form: 25 May 1983

D. K. Wagener

Department of Psychiatry

University of Pittsburgh

3811 O'Hara Street

Pittsburgh, PA 15213, USA 